\title{
Editorial
}

\section{La inflación en Colombia}

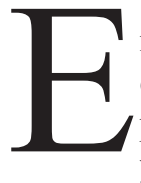

$\mathrm{n}$ los últimos meses, la inflación ha presentado un incremento notable. Desde febrero de 2015 ha estado por encima del límite superior del rango establecido entre 2 y 4 por ciento por el Banco de la República. Como se sabe, la inflación es el aumento continuo y sostenido del nivel general de precios, siendo uno de los objetivos de política económica en cualquier país. De allí, que la autoridad monetaria siempre va a utilizar los instrumentos necesarios para alcanzar la meta determinada en las proyecciones macroeconómicas.

El banco central de cada país fija la meta de inflación, teniendo en cuenta el tamaño y la dimensión de su economía. Es esencial alcanzar esta meta porque está de por medio la credibilidad de la autoridad monetaria, lo que es valioso para generar confianza y seguridad en los agentes económicos en que los objetivos se van a conseguir y que se van a utilizar las políticas necesarias.

No es ninguna novedad que la inflación trae consigo una serie de efectos adversos, por lo que es trascendental controlarla y mantenerla dentro de la meta establecida, por varias razones: en primer lugar, porque afecta la capacidad de compra que tiene el ingreso de los trabajadores. Este ingreso que está constituido, por lo general, por el salario que estos devengan, de tal suerte que si la inflación aumenta más que el incremento salarial, los trabajadores dispondrán cada vez de menos recursos para cubrir sus gastos. En otras palabras, la inflación actúa como un impuesto, ya que afecta negativamente a los trabajadores. En segundo lugar, porque incide en la redistribución del ingreso, golpeando a los más pobres, debido a que los productores trasladan el incremento de precios al consumidor final. Por lo anterior, el incremento general de precios contribuye a aumentar la desigualdad y la pobreza. En tercer lugar, porque tiene un impacto negativo en la competitividad, en la medida en que si la inflación se desborda, los bienes nacionales van a tener menores posibilidades de ser transados en los mercados internacionales. El resultado es que los agentes económicos preferirán productos procedentes de países con precios más bajos. Los argumentos atrás expuestos fundamentan una tasa de inflación baja y estable.

Por mandato constitucional, el Banco de la República propende a la conservación de la capacidad adquisitiva de la moneda, además tiene funciones como "regular la moneda, los cambios internacionales y el crédito; emitir la moneda legal; administrar la reservas internacionales", entre otras. La Constitución Política de Colombia puntualiza que "todas ellas se ejercerán en coordinación con la política económica en general". En este punto es necesario precisar que si bien la política económica hace referencia a la acción deliberada del Estado para alcanzar objetivos económicos en torno al crecimiento económico, el empleo y la inflación, 
así como un sector externo estable, parece que el Banco de la República solamente se interesa por mantener la capacidad adquisitiva de la moneda.

En los últimos meses, el banco emisor, en la medida en que la inflación ha desbordado el rango meta, ha implementado una política monetaria contraccionista, que ha llevado a que la tasa de interés -que se mantuvo en 4,5 por ciento desde el 1 de septiembre de 2014 hasta el 18 de agosto de 2015-, se incremente entre 0,25 y 0,50 puntos básicos, hasta ubicarse el 27 de mayo del presente año en 7,25 por ciento. Por otro lado, la inflación ha venido aumentando desde agosto de 2015 hasta abril del año en curso, a tal punto que durante el período mayo de 2015 abril de 2016 fue de 7,93 por ciento, mientras que para el mismo período del año anterior, fue de 4,64 por ciento. Esto significa que para el último año la inflación aumentó en 3,29 por ciento.

Aquí es necesario precisar, que la inflación causada en el último año se explica más por factores de oferta que de demanda, lo que justifica por qué se ha elevado la inflación, a pesar de las medidas aplicadas por el Banco. Entre los factores de costos se destacan el fenómeno de El Niño, que redujo notablemente la producción agrícola, y la devaluación del peso. Cabe recordar, que durante el último año (mayo de 2015 - a abril de 2016) el precio de los alimentos creció en 12,63 por ciento, y mes tras mes fue el rubro - de los ocho que componen la canasta familiar- con el incremento más alto. Además, la devaluación del peso, también se aceleró. En el período de referencia fue notable: mientras el 1 de mayo de 2015 la Tasa Representativa del Mercado fue de \$2393,58, el 30 de abril del año en curso alcanzó \$2851,14, presentándose una devaluación del 19 por ciento.

La devaluación encarece las importaciones y abarata las exportaciones. En el caso colombiano, dado el gran desabastecimiento de algunas materias primas y bienes de capital, pero sobre todo de alimentos de origen agrícola, el precio de las importaciones ha aumentado considerablemente. Las importaciones de los bienes agrícolas son cuantiosas, tanto que, según el ministro de Agricultura, Aurelio Iragorri, el país importó el 50 por ciento de frijol, el 60 por ciento de lenteja, el 40 por ciento de arroz, en trigo y maíz amarillo el ciento por ciento. Si se le agregan otros alimentos como frutas, es evidente el encarecimiento de los productos agrícolas.

El Banco de la República sostiene que la inflación se reducirá en el segundo semestre del presente año, y que la meta proyectada se alcanzará en el 2017. Obtenerla supone que la elevación de las tasas de interés impacte positivamente la demanda, que aumenten las cosechas por el inicio del período de lluvias y, por último, que se modere la devaluación. Empero, lo que queda claro es que el banco emisor utiliza un enfoque monetarista, coincidiendo con Milton Friedman, para quien: "la inflación es siempre y en todo lugar un fenómeno monetario". En esa perspectiva, elementos como "el déficit fiscal, las huelgas impulsadas por las centrales obreras, las variaciones en el precio del petróleo, entre otros", no perturbarán la inflación a mediano plazo, a no ser que generen un incremento de la cantidad nominal de dinero. 